work force? - that, by the way, was not the result of peer review". And he made no attempt to hide his distaste for "members of the scientific community going after money with all the grace of hogs going after truffles".

The final congressional decision on NCAM is still up in the air. The House of Representatives, after manoeuvring that first took \$5 million away from NCAM for a laboratory at Catholic University (see Nature 26 May, p.272), voted to delete all funds for construction from the 1984 appropriations. The Senate has voted to appropriate \$3 million, and the most likely outcome of the House-Senate conference - expected to take place this week - is some compromise between the two figures.

Another large project for which LBL has high hopes is the Tevalac, a proposed relativistic heavy-ion accelerator. LBL's reputation was early staked to its excellence in nuclear physics. But over the years, as the forefront of basic physics has passed to particle, or high-energy, physics, LBL has been left on the sidelines because it has never had one of the large high-energy accelerators.

The Tevalac would recapture for nuclear physics a piece of the action. As conceived in a plan drawn up late last year, it would extend the Bevalac concept - LBL's Bevalac last year became the first machine to accelerate uranium nuclei - to energies of $10 \mathrm{GeV}$ per nucleon at uranium. At these energies, the nuclear physics experiment of colliding nuclei yields a particle-physics payoff: a plasma of quarks and gluons

\section{Clinch River fast breeder The final blow?}

Washington

THE roller-coaster fortunes of the Clinch River fast breeder reactor in Tennessee hit a new low last week when the Senate decided to follow the example of the House of Representatives and exclude money for the project from its 1984 energy and water appropriations bill. Jubilant opponents of Clinch River claim that this will finally kill the project unless the nuclear industry offers to pay a much bigger share of the reactor's cost.

Construction of the power plant is expected to cost $\$ 3,500$ million, compared with an original estimate of around $\$ 700$ million. The industry contribution to the project has remained steady at about $\$ 250$ million despite the escalating costs. Congress is expected to renew funding for the programme only if the private sector is willing to raise its contribution to some $\mathbf{4 0}$ per cent of the overall costs and shoulder some of the financial risk entailed.

Although the Department of Energy (DOE) was last week considering a new financing proposal from the private sector, officials said the nuclear industry was unlikely to offer much more than the $\$ 800$ million proposed in a plan submitted to would be created, which, said Lee Schroeder, one of the Tevalac's developers, could be studied to learn the "thermodynamics" of quarks. This examination of bulk effects of quarks would complement the "microscopic", single quark view that a proposed electron accelerator will offer (see Nature 2 June, p.368).

The Tevalac's proponents are hoping for an endorsement by the Nuclear Science Advisory Committee (NSAC) when it meets on July 11-16 to draw up a five-year plan for nuclear physics. NSAC makes recommendations to the Department of Energy and the National Science Foundation on priorities in the field. The Tevalac will be vying with a proposal from Los Alamos National Laboratory to upgrade its LAMF accelerator (the Los Alamos Meson Facility) from $800 \mathrm{MeV}$ to $16 \mathrm{GeV}$ in order to study rare decay modes of certain particles. Brookhaven, CERN and the Gesellschaft fur Schwerionenforschung in West Germany are also considering construction of relativistic heavy-ion machines.

LBL planners say the Tevalac would not require additional staff, as savings in personnel would be realized by combining the operation centres of the present Superhilac and Bevalac. The total cost of the Tevalac is put at some $\$ 30$ million in research and development expenses and $\$ 100$ million in construction. Schroeder said that the most optimistic scenario would have construction begin in fiscal year 1986 and operation in 1990.

Stephen Budiansky

Congress in March. And the private sector will probably continue to insist that the government safeguard the industry's investment by promising to repay it through the sale of electricity generated by the plant.

By cutting off money for Clinch River at the end of the year, Congress is flying in the face of the Reagan Administration's policy of continuing work under the existing financial arrangements. The administration had requested $\$ 270$ million for work on the reactor in 1984.

Just what will happen at the reactor site if there is no agreement between Congress and the industry remains unclear. Senator Mark Hatfield (Republican, Oregon) said last week that the Senate's intention was to bring all work on the site - including basic preparation of the ground - to a complete halt. But he warned that DOE might be able to continue work if Congress was once again forced to operate under a continuing resolution.

A spokesman for DOE confirmed that the legal status of Clinch River is likely to be ambiguous. Technically, the project remains authorized and there is no specific language in the appropriations bill declaring it suspended. If the project were indeed allowed to die, he added, Congress would have to appropriate some money in 1984 to meet close-down costs.

Peter David

\section{Koestler's last laugh}

ArThUR Koestler and his wife Cynthia, who committed suicide together last March, must have relished the prospect that their bequest to establish the first chair in parapsychology at a British university would set a cat among the academic pigeons. By last week, when news of the $\mathbf{1 5 0 0 , 0 0 0}$ bequest became known, no university had grasped the nettle, but discussions were in progress with several.

Koestler's last years were marked by an increasing fascination with parapsychology, leading to two books on the subject. He wrote in his suicide note of his "timid hopes of a depersonalized afterlife". Now it is up to Dr John Beloff, senior lecturer in psychology at the University of Edinburgh

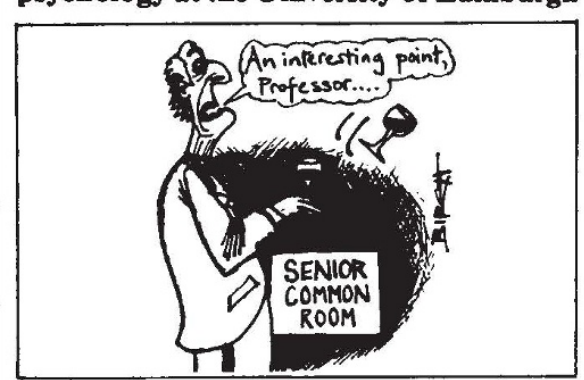

and the executor handling the Koestler bequest, to persuade a university to take up the offer. Beloff is negotiating with several universities, including those at Edinburgh and Cambridge, but admits there have been difficulties. The terms of the bequest make it clear that it should fund research into parapsychology itself, rather than, for example, the factors affecting belief in such phenomena. Koestler left no instructions about how the money should be used if early research fails to produce evidence of paranormal forces, and many universities may be reluctant to accept the bequest if it is tied to this field in perpetuity. If it proves impossible to set up a chair, the terms of the bequest allow a number of research fellowships to be established instead.

Mr I Bloomfield of the KIB Foundation, a charity that Koestler helped to set up to fund research beyond scientific orthodoxy, has pledged to put the interest from a sum equivalent to the Koestler bequest towards the research of the proposed professor of parapsychology. Together with the Koestler bequest, this sum would enable a university to set up a unit of perhaps five or six workers. Dr Beloff will also be seeking research funds from the Parapsychology Foundation in New York. No firm decisions have been taken on what facilities would be needed for the new unit, but Beloff is looking for the offer of a laboratory and shared secretarial services, perhaps within an existing psychology department. Disinterested academics may be invited to advise on the provision of equipment. Dr Beloff hopes the chair will be established by October 1984.

Tim Beardsley 